\title{
Cupping Therapy (Al-Hijamah): An Exploratory Study of Healthcare Professionals Controversial Beliefs and Conceptions, Kingdom of Saudi Arabia
}

\author{
Ahmed T. El-Olemy ${ }^{1,2}$, Abdullah M. Al-Bedah ${ }^{1}$, Ahmed H. Almosilhi ${ }^{1}$, \\ Jawaher A. Almusailhi ${ }^{3}$, Asim A. Hussein ${ }^{1}$, Mohamed Khalil', \\ Tamer S. Aboushanab", Ibrahim M. Elsubai ${ }^{1}$, Meshari S. Alqaed", \\ Gazzaffi I. M. Ali ${ }^{1}$, Sulaiman Al-Eidi ${ }^{1}$ and Naseem A. Qureshi ${ }^{1 *}$ \\ ${ }^{1}$ National Center for Complementary and Alternative Medicine, Ministry of Health, Riyadh, \\ Saudi Arabia. \\ ${ }^{2}$ Department of Public Health and Community Medicine, Faculty of Medicine, Tanta University, Egypt. \\ ${ }^{3}$ Imam Abdulrahman Alfaisal University, Dammam, Saudi Arabia.
}

\section{Authors' contributions}

This work was carried out in collaboration between all authors. Authors ATEO, TSA and AAH designed the study. Authors ATEO, AMAB, NAQ and MK performed the statistical analysis. Authors ATEO, AHA and NAQ wrote the protocol. Authors ATEO, NAQ, TSA and MSA wrote the first draft of the manuscript. Authors NAQ and TSA revised the paper a number of times. Author NAQ finalized the paper. All authors helped in the management of the literature searches. All authors read and approved the final manuscript.
Article Information
DOI: $10.9734 / J O C A M R / 2017 / 34835$ Editor(s):
(1) Nawal Kishore Dubey, Centre for Advanced Studies in Botany, Banaras Hindu University, India.
Reviewers:
(1) Oroma Nwanodi, A.T. Still University, USA.

\section{ABSTRACT}

Background: Cupping therapy (Al-Hijamah) is a traditional therapy, supported and practised by people around the world since ancient times. Cupping therapy related to complementary and alternative medicine is associated with controversial, false beliefs and misconceptions.

Objective: This study aimed at exploring controversial beliefs and conceptions about cupping therapy among healthcare professionals, Riyadh, Kingdom of Saudi Arabia (KSA). 
Methods: A cross-sectional study involving 241 healthcare professionals was carried out from January to June 2016. All participants requesting license for practicing cupping therapy underwent one week Al-Hijamah training course at National Center for Complementary and Alternative (NCCAM). Prior to training course, all subjects completed a 23-item predesigned questionnaire related to controversial beliefs and misconceptions concerning cupping therapy. All participants gave written informed consent.

Results: Healthcare professionals who participated in the study $(n=241)$ were 93 physicians, 56 physiotherapists, 61 nurses and 31 other specialists. Saudi participants represented $46.1 \% .60 .6 \%$ were adult males with mean clinical experience of $13.0 \pm 9.37$ years. "Al-Hijamah gets rid of bad blood" was the commonest controversial belief reported by $68.1 \%$ of participants. A proportion of participants (31.5\%) reported "Al-Hijamah is absolutely safe" and "Al-Hijamah is effective in the treatment of all diseases". The least controversial beliefs reported by $12 \%, 8.7 \%$ and $2.9 \%$ of participants were "Cupping can be used for all patients and all diseases", "Cupping like a blood donation is not different" and "The scarification of cupping (in wet cupping) must be deep", respectively.

Conclusion: The explored controversial beliefs and misconceptions related to cupping therapy may impact knowledge, attitude and practice of cupping practitioners. Therefore, all healthcare professionals need to be regularly exposed to a training course targeting these beliefs and misconceptions concerning cupping therapy prior to giving them license for practicing this traditional modality. Continuing research in cupping mechanisms of action is another prioritized area which can provide scientific explanations underlying its efficacy and outcome together with alleviating its false beliefs and misconceptions.

Keywords: Cupping beliefs; misconceptions; healthcare professionals; cupping training; mechanisms; licensing; Saudi Arabia.

\section{INTRODUCTION}

Cupping therapy (in Arabic Al-Hijamah) is a traditional folk therapy practiced by people worldwide since ancient times [1,2]. Initial reports of cupping had been found in Egyptian and Chinese scriptures; however, the first description of cupping is traced in Ebers Papyrus which is one of the oldest medical textbooks written in 1550 BC. Subsequently, cupping was passed on to the Greeks and Romans [2,3]. In the Arab and Muslim world, Al-Hijamah is a deeply rooted religious technique supported by many authenticated sayings (hadiths) of Prophet Mohammad (PBUH) who recommended its use in human ailments more than 1400 years ago [2]. However, the western nations were unaware of its useful applications in human ailments until mid-twenty century [2,4]. Over centuries, the cups and cupping techniques have changed; however, its beneficial effects were increasingly recognized both by the cupping practitioners and users [5] along with keen interest in research on cupping therapy. Cupping is used in several medical conditions with good results [2]. Cupping relies upon creating a local suction to mobilize blood flow to the affected area to promote healing together with removal of toxic substances from the blood to treat diseases [6]. The innovative research on cupping mechanisms of action is expanding around the world [7].
The epidemiological trend of cupping therapy varies across the world. In Saudi Arabia, AlHijamah is ranked the fourth most prevalent traditional therapy, used by $35.7 \%$ of its population. Medical herbs (58.9\%), spiritual practices $(54.6 \%)$ and honey and bee products (54.3) [8] are the most prominent traditional modalities. Health professionals in KSA stated that $24.7 \%$ of the population use Al-Hijamah as a CAM modality and $52.2 \%$ of them believed in its efficacy [9]. At the same time, $13 \%$ of patients attending primary health care centers were reported to use cupping therapy in KSA [10]. Like other healing practices, lack of evidencebased data in cupping is one of the challenges that impede its official, clinical use and regulation in most countries [11]. Traditional healers claimed that wet cupping in particular requires only a few days training course to be able to practice cupping. Furthermore, cupping healers suggest that no specific qualifications are required and any person can practice it. In most countries, there was no formal training undertaken by cupping therapists [12]. Some of these views of traditional practitioners and healthcare professionals reflect their false beliefs and misconceptions about cupping trends, practices, regulation, training and required education.

A study from NCCAM reported controversial beliefs and misconceptions about cupping (Al- 
Hijamah) therapy in Saudi Arabia. This research classified beliefs into seven categories including 27 beliefs and conceptions. Five beliefs and conceptions were related to either tools used for cupping or color or type and amount of blood. Four beliefs were about either scarification or patient preparation before and disposal after cupping. Furthermore, three beliefs and conceptions were communicated in terms of either infection control or indication of cupping therapy by its practitioners [13]. The significance of this pilot study is that it explores a topic which is seldom researched across the world. This study will encourage other researchers and health professionals in Saudi Arabia and elsewhere in the world to conduct better quality studies on false beliefs associated with cupping technique and its tools. As Al-Hijamah has religious connotation, the associated false beliefs with this traditional therapy need to be corrected among practitioners, healthcare professionals and public at large. The aim of this preliminary study was to explore controversial beliefs and conceptions associated with cupping therapy (AlHijamah) among healthcare professionals in Saudi Arabia.

\section{METHODS}

\subsection{Design}

A cross-sectional study.

\subsection{Setting}

National Center for Complementary and Alternative Medicine, Riyadh, Saudi Arabia.

\subsection{Sample}

The sample included all healthcare professionals who attended NCCAM for getting license to practice Al-Hijamah during the period of January to June 2016. Notably, all participants took one week training course in Al-Hijamah therapy. Health professionals $(n=241)$ participated in the study were as follows: 93 physicians, 56 physiotherapists, 61 nurses and 31 other specialists.

\subsection{Inclusion and Exclusion Criteria}

The main inclusion criterion was that the healthcare professionals' visit to NCCAM was for receiving license for practicing cupping in Saudi Arabia along with taking one week of intensive training course in cupping therapy. The exclusion criterion was applied when the healthcare professional disagreed to participate in the study. However, none of them was denied the right to receive license for practicing cupping therapy. Similarly, all participants took one week intensive course on cupping therapy and cupping tools.

\subsection{Procedure}

The first author distributed 23-item predesigned questionnaire to participants who were advised to fill out it completely. This step was taken prior to the one week training course in cupping therapy organized multiple times in NCCAM, Riyadh. All participants self-answered a pretested questionnaire. Any query raised by the participant was promptly clarified by a specified team member. The questionnaire was consisted of 23 statements that explored the commonest and most important controversial beliefs and conceptions about traditional cupping therapy. Only 15 minutes are needed to fill out the questionnaire. All the questionnaires were returned to one of the co-author (ATEO) who ensured that all questionnaires were filled out completely.

\subsection{Questionnaire}

The questionnaire was developed by a team of four experts in cupping therapy. The experts, all from NCCAM, designed a semi-structured questionnaire using the results of a study [11], which explored false beliefs of public in Saudi Arabia. In the first phase, the team constructed 52 tentative items on controversial beliefs, misconceptions, and conceptions. In the second stage, the long list of 52 items was shortened into 23, which were mostly false statements. Furthermore, they discuss each item carefully for its clarity, readability and comprehensiveness. They suggested some modifications with the wordings and appropriateness of few statements in the questionnare. All team members agreed on all 23 items reaching 100\% agreement with good reliability. A pilot study was conducted on 10 participants (not included in the final sample) for testing the questionnaire and final tuning was done concerning technical words. The final, selfadministered questionnaire is consisted of 23 items mostly of false beliefs (available upon request from $A T E O$ and $N A Q$ ), to be judged by the participants as false or true.

\subsection{Data Management and Analysis}

Data was entered in the computer. Data was cleaned and analyzed using SPSS statistical 
package for windows version 20. Mean, Standard Deviation (SD) and analysis of variance (ANOVA) were used to analyze quantitative data. Frequency distribution and percentages were calculated and chi square test was used to analyze qualitative, categorical data. $\mathrm{P}<0.05$ was considered significant.

\subsection{Ethical Consideration}

All participants were informed in non-technical language about the aims and objectives of this study. Any query raised by individual participant was clarified quickly. They were also informed that their nonparticipation will not affect the course attendance and license will be issued following course completion. They were also informed that this study is without any risk. Answering the questionnaire was considered as an informed consent to participate in the study. In addition, each healthcare professional gave written consent for participating in this study. The study protocol was approved by the Ethical Committee of the NCCAM, Riyadh, Saudi Arabia.

\section{RESULTS}

Two hundred and forty one healthcare professionals participated in this study; 93 physicians $(38.6 \%)$ with a mean age of $41.97 \pm 12.15$ years and a mean duration of experience $18.02 \pm 12.2$ years. Physiotherapists were $56(23.2 \%)$ with a mean age of $32.46 \pm 8.2$ years and a mean duration of experience $10.48 \pm 8.18$ years. Nurses $(n=61)$ represented $25.3 \%$ with a mean age of $35.49 \pm 9.3$ years and a mean duration of experience 15.31 \pm 10.23 years. Saudi participants $(n=111)$ represented $46.1 \%$ and non-Saudi $(n=130)$ constituted $53.9 \%$. Among them, $60.6 \%$ were males $(n=146)$ and $39.4 \%(n=95)$ were females. There were significant differences between different specialties of participants concerning age, gender, nationality and years of experience $(p<0.05)$ (Table 1).

The responses of all participants to 23 items are shown in Table 2. "Al-Hijamah gets rid of bad blood (Dam Fased in Arabic)" was the commonest controversial false belief among two thirds of participants (68.1\%). About $43.6 \%$ of participants reported incorrectly that "Alkahel area (the area from the base of the neck below the level of $7^{\text {th }}$ cervical vertebra to $3^{\text {rd }}$ thoracic vertebra) is used for cupping therapy in all diseases". Another $40.3 \%$ stated falsely that "The color of blood inside the cup is an indication of the severity of the disease". Furthermore, "The darker the cupping blood, the greater the severity of the disease" is reported incorrectly by $36.1 \%$ of subjects. About one third of participants reported that "Al-Hijamah is absolutely safe" which is not the case and it is a misconception. Notably, similar number of subjects reported that "Al-Hijamah is effective in the treatment of all diseases" is not correct and is a misbelief.

Table 1. Sociodemographic characteristic of studied subjects

\begin{tabular}{|c|c|c|c|c|c|}
\hline Variables & $\begin{array}{l}\text { Physicians } \\
\mathrm{N}=93\end{array}$ & $\begin{array}{l}\text { Physiotherapists } \\
N=56\end{array}$ & $\begin{array}{l}\text { Nurses } \\
\mathrm{N}=61\end{array}$ & $\begin{array}{l}\text { Others } \\
\mathrm{N}=31\end{array}$ & $\begin{array}{l}\text { Total } \\
\mathrm{N}=241\end{array}$ \\
\hline \multicolumn{6}{|c|}{$x_{0}$} \\
\hline Range & $26-78$ & $23-55$ & $24-55$ & $23-52$ & $23-78$ \\
\hline Mean & 41.97 & 32.46 & 35.49 & 29.87 & 34.95 \\
\hline S.D. & \multirow{2}{*}{\multicolumn{5}{|c|}{$\mathrm{F}=16.91, P=0.0000$, sig. }} \\
\hline Gender & & & & & \\
\hline Male & $63(26.1)$ & $33(13.7)$ & $28(11.6)$ & $22(9.1)$ & $146(60.6)$ \\
\hline Female & \multirow{2}{*}{\multicolumn{5}{|c|}{$x^{2}=9.05, P=0.03$, sig. }} \\
\hline Nationality & & & & & \\
\hline Saudi & $34(14.1)$ & $29(12.0)$ & $20(8.3)$ & $28(11.6)$ & $111(46.1)$ \\
\hline Non-Saudi & \multirow{2}{*}{\multicolumn{5}{|c|}{$x^{2}=32.69, P=0.000$, sig. }} \\
\hline Experience & & & & & \\
\hline Range & $2-53$ & $2-33$ & 3-35 & $1-32$ & $1-53$ \\
\hline Mean & 18.02 & 10.48 & 15.31 & 8.19 & 13.0 \\
\hline S.D. & \multicolumn{5}{|c|}{$\mathrm{F}=10.99, P=0.0000, \mathrm{sig}$} \\
\hline
\end{tabular}


In addition, a similar number of participants stated that "You must put the cup after scarifications several times until yellow liquid is out" which is also incorrect. About $28.6 \%$ of participants stated that "Scarifications covering the entire area of the cup increase the effectiveness of cupping" which is also false conception.

About $25 \%$ of participants stated incorrectly that "There is no need to disinfect the cups before cupping". A similar number of participants (25\%) reported falsely that "There is no need to cover the cupping points with a medical dressing after Al-Hijamah". Furthermore, 25\% of the subjects stated that "If blood does not come out after scarification you should repeat it once again" which is a misconception. Another $25 \%$ of participants stated that "The amount of blood inside the cup is a sign of the severity of disease" which is a false belief. "Shaving razors can be used for scarification for cupping" is reported by $17.8 \%$ of participants, and that is a potentially dangerous misconception. "Hand washing is not the key component of infection control" is stated by $16.6 \%$ of participants, and this is quite wrong conception.

The least controversial belief stated by $2.9 \%$ of participants was "The scarification of cupping must be deep" but it is also a misconception (Table 2). Finally, no significant differences between different specialties of participants and controversial beliefs and conceptions were observed ( $p>0.05)$ (Table 3).

\section{DISCUSSION}

This study explored controversial beliefs of 241 participants concerning cupping therapy in Saudi Arabia. The term Al-Hijamah refers to the Arabic traditional practice of wet cupping in which vacuum is created by applying hollow cup to the affected area and toxic blood is drawn from small

Table 2. Controversial beliefs and conceptions about Al-Hijamah among studied subjects $(n=241)$

\begin{tabular}{lll}
\hline Controversial beliefs and conceptions & $\begin{array}{l}\text { Number } \\
\text { N=241 }\end{array}$ & $\%$ \\
\hline $\begin{array}{ll}\text { 1. Al-Hijamah gets rid of bad blood (Dam Fased in Arabic) } \\
\text { 2. Alkahel area (the area from the base of the neck below the level of 7th } \\
\text { cervical vertebra to 3rd thoracic vertebra) is used for cupping all }\end{array}$ & 164 & 68.05 \\
diseases & & 43.57 \\
3. The color of blood inside the cup is an indication of the severity of the & 97 & 40.25 \\
disease & & \\
4. The darker the cupping blood, the greater the severity of the disease & 87 & 36.10 \\
5. You must put the cup after scarifications several times until yellow liquid & 77 & 31.95 \\
out & 76 & 31.54 \\
6. Al-Hijamah is absolutely safe & 76 & 31.54 \\
7. Al-Hijamah is effective in the treatment of all diseases & 69 & 28.63 \\
8. Scarifications covering the entire area of the cup increase the & \\
effectiveness of cupping & 65 & 26.97 \\
9. There is no need to disinfect the cups before cupping & 57 & 23.65 \\
10. There is no need to cover areas of scarification with a medical dressing & 57 \\
after Al-Hijamah & & 21.99 \\
11. The amount of blood inside the cup is a sign of the severity of disease & 53 & 21.99 \\
12. If blood does not come out after scarification you should repeat it once & 53 & \\
again & & 17.84 \\
13. Shaving razors can be used for scarification for cupping & 43 & 16.60 \\
14. Hand washing is not the key component of infection control & 40 & 15.35 \\
15. Cupping is useful in emergencies & 37 & 15.35 \\
16. The longer the cup is placed on the skin the more effective is cupping & 37 & 14.52 \\
17. The greater the number of cups the more effective cupping process & 35 & 13.69 \\
18. The amount of blood inside the cup indicates the degree of healing & 33 & 13.28 \\
19. It is possible to perform wet cupping (Al-Hijamah) anywhere in the body & 32 & 12.86 \\
20. Cupping does not cause the transmission of infectious diseases & 31 & 12.03 \\
21. Cupping can be used for all patients and all diseases & 29 & 8.71 \\
22. Cupping like blood donation is not different & 21 & 2.90 \\
23. The scarification of cupping must be deep & 7 & \\
\hline
\end{tabular}


Table 3. Controversial beliefs and conceptions about traditional cupping according to specialties

\begin{tabular}{llllll}
\hline Characteristics & $\begin{array}{l}\text { Physicians } \\
\mathbf{N = 9 3}\end{array}$ & $\begin{array}{l}\text { Physiotherapists } \\
\mathbf{N = 5 6}\end{array}$ & $\begin{array}{l}\text { Nurses } \\
\mathbf{N = 6 1}\end{array}$ & $\begin{array}{l}\text { Others } \\
\mathbf{N = 3 1}\end{array}$ & $\begin{array}{l}\text { Total } \\
\mathbf{N = 2 4 1}\end{array}$ \\
\hline Controversial beliefs $\mathbf{( N = 2 3 )}$ & & & & \\
Range & $1-14$ & $2-16$ & $1-16$ & $1-14$ & $1-16$ \\
Mean & 5.61 & 6.61 & 6.48 & 5.81 & 6.13 \\
S.D. & 2.82 & 3.09 & 2.96 & 2.91 & 2.95 \\
Confidence interval & $5.01-6.21$ & $5.84-7.38$ & $5.74-7.22$ & $4.77-6.85$ & $5.67-6.5$ \\
& $\mathrm{~F}=1.848, P=0.138$, Insignificant & & & \\
\hline
\end{tabular}

skin incisions (scarification) [14,15]. Cupping therapy, an ancient modality, is ranked fourth among local traditional CAM practices in KSA. Wet cupping has been used locally for preventive or therapeutic purposes by both the general population and the patients $[8,10,16]$. Currently, wet or dry cupping is used in many diseases and practiced mostly by traditional healers around the world [2,17].

Belief systems concerning medical sciences and related practices are prevalent in diverse societies [18]. Cultural beliefs about traditional practices as well as conventional medicine survived since ancient times because of their explanatory power and therapeutic values. However, some of these beliefs about traditional therapies such as cupping among professionals and public may be scientifically false and controversial because of lack of education, campaigns and teaching cupping therapies in medical and health allied curricula and courses [19]. In addition, controversial beliefs and conceptions about cupping are attributed to the lack of regulation, research, professional training and teaching in all medical schools. Furthermore, non-qualified practitioners also contribute to the false belief pool related to cupping therapy [20-22]. The underlying mechanisms of cupping therapy are not known and, hence, appear to play an important role in sustaining these controversial beliefs $[13,17]$. Notably, in other words, absence of highly qualified and robust studies on mechanism of action, lack of scientific foundation and malpractice related to cupping therapy tend to complicate the entire belief system concerning cupping technique $[2,7,13,17]$.

False beliefs concerning Al-Hijamah categorically need to be changed. In this direction, NCCAM took a step forward to legalize cupping in KSA in 2015. Since then, Al-Hijamah is practiced only by qualified healthcare professionals who take the prescribed, comprehensive training course in cupping therapy under the supervision of NCCAM. One of the topics of this one-week intensive course is a detailed discussion of false beliefs about cupping therapy. It is wise to know that the NCCAM is the national reference for all activities of complementary and alternative medicine in Kingdom of Saudi Arabia [23]. Arguably a fair discussion related to cupping false beliefs and misconceptions among healthcare professionals practicing cupping therapy will certainly ameliorate incorrect notions about cupping therapy, and this intensive training model might be adopted by other Gulf countries.

According to one of the NCCAM's scientific surveys, health professionals' sources of information about CAM in Saudi Arabia were reported to be the internet, relatives and friends. However, teaching in medical schools, conferences, research papers and trusted journals were rarely reported [16], which are the sources of correct information including beliefs about cupping technique practices and other traditional therapies. Therefore, it is not surprising to find varying controversial beliefs and misconceptions about Al-Hijamah among healthcare professionals in the present study. The commonest controversial belief related to cupping was "Al-Hijamah gets rid of bad blood". Unfortunately, this is a famous postulation proposed by most of Arabic authors' writings and text books who were themselves well-known traditional healers [24-26]. This term "bad blood inside the body" doesn't make any scientific sense. Rather the correct belief is that blood carries pathological end products, toxins and metabolites [7] which are removed by Al-Hijamah therapy.

According to this study, the second commonest controversial belief was "Alkahel area is used for cupping of all diseases". This is written in traditional books of cupping but without any robust explanation [27-29]. Also, training courses 
of cupping conducted by mostly unofficial training centers transmit the same belief [30]. This is a scientifically unclear and probably wrong assumption. The Alkahel area is one of the most important Hijamah points; however, it is not used for the management of all diseases. This area has some special features; brown adipose tissue related to main vessels carrying blood from the heart and the brain, passage of the thoracic duct, immediate proximity to the sympathetic stellate ganglia and two acupuncture meridians. So in cupping therapy, Alkahel is used in more than one disease but not all diseases [31]. For example, in case of musculoskeletal disorders, painful points rather than Alkahel area are used for cupping. Another common false belief about cupping stated by the participants is "Al-Hijamah is absolutely safe and effective in the treatment of all diseases". Certainly, Al-Hijamah is relatively safe with good safety profile but not in absolutely terms [32]. Notably, some adverse events have been reported with cupping such as discoloration, swelling, burns, ulcers, dermatitis bullae, infection, anemia, and scar formation [32]. Concerning efficacy, although Al-Hijamah is used as a complementary therapy in many diseases; it has no role in congenital disorders and fractures [33,34]. According to this study, "Scarification covering the entire area of the cup increases the effectiveness of cupping" is wrongly reported by more than one fourth of health professionals. In reality, scarifications in most of the researches concerning wet cupping ranged from 6-12 numbers; one cupping session with scarifications involving 6 to 12 superficial cuts is recommended procedure in wet cupping. However, the number of scarification may differ according to the size of the cup. Cupping therapists use either sterile surgical blade or auto-lancet for scarification. No research recommended scarifying all the area under the cup [35].

Cupping therapy is known to produce infection in case disinfection measures are not taken by cupping therapists. According to this research, many controversial beliefs and conceptions were found among healthcare professionals. Some are obviously false beliefs but others are scientifically debatable. According to healthcare providers' beliefs, Al-Hijamah can be performed anywhere in the body. This is certainly a risky practice and wrong belief. Cupping therapy is precisely done over an infected skin lesion e.g. boils, abscess or carbuncle. Other false beliefs and misconceptions stated by healthcare professionals were related to 'not washing hands', 'use of shaving razor for scarification', 'not covering the area of scarification with sterile wound dressing' and 'the use of cups without disinfection', and all these potentially dangerous practices evidently contradict proper infection control measures [36]. Such controversial beliefs and conceptions related to infection control measures can obviously increase the incidence of wound infection, longer time in healing, scar formation, and spread of blood borne diseases. In addition, such practices may also lead to an increase incidence of infection to nearby environment, relatives and caregivers and practitioners. Some cases may require hospitalization with an additional overload on healthcare services [37].

According to this exploratory research, many false beliefs and misconceptions concerning the effectiveness of wet cupping were reported by the participants. For example, cupping therapy outcome or effectiveness is related to the amount and color of blood inside the cup, increasing the number of cups to be used, prolonging the duration of cupping, and increasing the number and depth of scarification. These false beliefs need to be corrected by intensive training courses targeting cupping therapists in Saudi Arabia and other Gulf countries. Obviously, there are diverse implications including complications of false beliefs. Using shaving razors, re-putting the cup several times on the cupping points, repeating deep scarification, and doing wet cupping on prohibited areas such as varicose veins, arteries or nerves all predispose to potential risk for scar formation, infections, injury to a nerve or vessel, dermatitis bullae, burns and blood loss resulting in anemia [32,38-41]. Furthermore, with regard to cupping therapy points and its indications, the participants revealed many controversial beliefs and conceptions such as practitioners' use of extra number of points without any indication, use of cupping technique in the treatment of certain diseases without any evidence including emergency cases. Al-Hijamah should not be used for emergency cases because it may potentially undermine patients' condition by losing time for medical intervention and even lifesaving procedures. Overall, continuation of controversial beliefs and misconceptions in AlHijamah practice now certainly conflict with medical and research ethics [42] and associated with various adverse clinical consequences and, therefore, needs corrective targeted programs including training and campaigns directed 
towards Al-Hijamah practitioners as well as public around the world. In addition, mechanisms of cupping action linked with scientific explanations of its modus operandi, related effects and effective outcomes in various diseases $[43,44]$ will help in alleviating the false beliefs and misconceptions associated with cupping.

This tentative study has some limitations. This study includes relatively small sample and the participants are heterogeneous. This is because only medical professionals namely physicians, physiotherapists and nurses are allowed to practice cupping in KSA at present time. According to the current Al-Hijamah regulations approved by NCCAM, other medical and paramedical healthcare professionals are not allowed to use cupping therapy in Saudi Arabia. The true-false responses of the participants on the questionnaire do not give an idea how powerfully they hold these beliefs. Use of 5-point Likert scale would have been better option.

This exploratory study has some strengths. This pilot research has reported a $100 \%$ response rate and, hence, the study reflects rigorousness without any selection bias. All health professionals completed all the items on the questionnaire, another sign of soundness of this study. It is the first exploratory study that meticulously explored controversial beliefs and conceptions associated with Al-Hijamah therapy in the world. This study may encourage other researchers to explore false beliefs concerning Al-Hijamah practices not only in Saudi Arabia but also in the Arabic and Islamic countries. Discussing this controversial topic during NCCAM training courses would provide a solid platform to change health professionals' false concepts and beliefs concerning cupping therapy. Ultimately, Al-Hijamah practitioners taking these training courses will disseminate and deliver correct beliefs about cupping not only to the patients but also the communities in Kingdom of Saudi Arabia. As Al-Hijamah/cupping therapy has multiple clinical applications, used across the world [45] and has religious connotations, time has arrived when all false beliefs associated with it need to be corrected and removed radically

\section{CONCLUSION}

In summary, this tentative study found many false beliefs and misconceptions concerning cupping therapy among healthcare professionals that may influence their knowledge, practice and attitude towards cupping therapy. In order to practice cupping in safe and most effective way, all healthcare professionals need to be regularly exposed to intensive training program targeting controversial beliefs and conceptions prior to giving license for practicing Al-Hijamah. Clinical practice guidelines for cupping therapists also need to be in place in all cupping centers in Saudi Arabia. Furthermore, high quality scientific studies related to cupping controversial beliefs and misconceptions should be prioritized and encouraged in future in Saudi Arabia and other Gulf countries.

\section{CONSENT}

All subjects gave written consent for participation.

\section{ETHICAL APPROVAL}

The research protocol was approved by the Ethical Committee of National Center for Complementary and Alternative Medicine, Riyadh, Saudi Arabia.

\section{COMPETING INTERESTS}

Authors have declared that no competing interests exist.

\section{REFERENCES}

1. Tamer Shaban. Cupping therapy encyclopaedia, January 5; 2014.

ISBN-13: 978-1494780517

2. Qureshi NA, Shaban T, Elsubai IS, Alqaed MA, Gazzaffi I, El-Olemy AT, Al-Bedah AM. History of cupping (Hijama): A narrative review of literature. Journal Integrative Medicine. 2017;15(3):172-181.

3. Chirali IZ. The cupping procedure. In: Chirali IZ. Traditional Chinese medicine cupping therapy. London: Churchill Livingstone. 1999;73-86.

4. Bondok SMA. Cupping the great missing therapy. Cairo, Dar Al-Salam; 2006.

5. Al-Bedah AM, Aboushanab TS, Alqaed MS, Qureshi NA, Suhaibani I, Ibrahim G, Khalil M. Classification of cupping therapy: A tool for modernization and standardization. Journal Complementary Alternative Medical Research. 2016;1(1): 1-10. 
6. Ullah K, Younis A, Wali M. An investigation into the effect of cupping therapy as a treatment for anterior knee pain and its potential role in health promotion. The internet Journal Alternative Medicine. 2007;4(1).

DOI: $10.5580 / 796$

7. El Sayed SM, Mahmoud HS, Nabo MMH. Medical and scientific bases of wet cupping therapy (Al-Hijamah): In light of modern medicine and prophetic medicine. Alternative Integrative Medicine. 2013;2:116.

8. El-Olemy AT, Al-Bedah AM. Public knowledge, attitude and practice of complementary and alternative medicine in Riyadh Region, Saudi Arabia. Oman Medical Journal. 2012;27(1):20-26.

DOI: 10. 5001/omj.2012.04

9. AlBedah AM, El-Olemy AT, Khalil MK. Knowledge and attitude of health professionals in the Riyadh region, Saudi Arabia, toward complementary and alternative medicine. Journal Family and Community Medicine. 2012;19(2): 93.

10. AlBedah AM, Khalil MK, El-Olemy AT, AI Mudaiheem AA, Al Eidi S, Al-Yahia OA, AlGabbany SA, Henary BY. The use of and out-of-pocket spending on complementary and alternative medicine in Qassim province, Saudi Arabia. Annals Saudi Medicine. 2013;33(3):282-289.

11. Abdullah AM, Khalil MK, Posadzki P, Sohaibani I, Aboushanab TS, AIQaed M, Ali Gl. Evaluation of wet cupping therapy: Systematic review of randomized clinical trials. The Journal Alternative Complementary Medicine. 2016;22(10): 768-777.

DOI: $10.1089 / \mathrm{acm} .2016 .0193$

12. Chen B, Li MY, Liup PD, Guo Y, Chen ZL. Alternative medicine: An update on cupping therapy. Quality Journal Medicine. 2015;108:523-525.

13. National Center for Complementary and Alternative Medicine. Beliefs and misconceptions in practicing cupping: Question and answer.

DOI: $1796 / 1438$

ISBN: 6-5-90708-603-978

14. Al-Bedah AM, Aboushanab TS, Alqaed MS, Qureshi NA, Basahi JA, El-Olemy AT, Khalil M. The use of medical simulation in cupping therapy training: A novel idea from the national center for complementary and alternative medicine. Journal Complementary Alternative
Medical Research. 2016;1(3):1-4. Article no. JOCAMR.30027.

DOI: 10.9734/JOCAMR/2016/30027

15. Ahmedi M, Siddiqui MR. The value of wet cupping as a therapy in modern medicine - An Islamic Perspective. Webmed Central Alternative Medicine. 2014;5(12): WMC004785.

16. Al-Rowais NA, AIBedah AM, Khalil MK, ElOlemy AT, Hussein AA, Al-Rasheid $\mathrm{MH}$, Al-Khashan $\mathrm{H}$, Al-Yousef $\mathrm{M}$, Ba Fart AA. Knowledge and attitudes of primary health care physicians towards complementary and alternative medicine in the Riyadh Region, Saudi Arabia. Forschende Komplementärmedizin/Research in Complementary Medicine. 2012;19(7):712.

17. AlBedah AM, Khalil MK, El-Olemy AT, Hussein AA, AlQaed M, Al Mudaiheem A, Abutalib RA, Bazaid FM, Bafail AS, Essa $A B$, Bakrain MY. The use of wet cupping for persistent nonspecific low back pain: Randomized controlled clinical trial. The Journal Alternative Complementary Medicine. 2015;21(8):504-8.

DOI: $10.1089 / \mathrm{acm} .2015 .0065$

18. U.S. Department of Health and Human Services. Culture Counts: The Influence of Culture and Society on Mental Health (Chapter 2). In: Mental Health: Culture, Race, and Ethnicity-A Supplement to Mental Health: A Report of the Surgeon General. Rockville, MD: U.S. Department of Health and Human Services, Substance Abuse and Mental Health Services Administration, Center for Mental Health Services; 2001.

Bookshelf ID: NBK44243

PMID: 20669516

19. Al-Rukban MO, AlBedah AM, Khalil MK, El-Olemy AT, Hussein AA, Alrasheid MH. Status of complementary and alternative medicine in the curricula of health colleges in Saudi Arabia. Complementary Therapies Medicine. 2012;20:334-339.

20. AlBedah A, Khalil M. AIQaed M, Qureshi NA, EIOlemy A, EISubai I, Asim Khalil A. The effect of introducing complementary medicine course in the curricula of undergraduate medical students on changing the attitudes towards CAM. Integrative Medical Research. 2015;42144.

21. El-Olemy AT, Radwan NM, Shihab NS, Dawood WM. Knowledge, attitudes, and practices of non-medical students in 
traditional and complementary medicine in Gharbiya Governorate, Egypt: A crosssectional study. Forschende Komplementärmedizin / Research Complementary Medicine. 2014;21(5): 314-319.

22. El-Olemy AT, Radwan NM, Dawood WM, Abu Ali I, Fouda LM. Complementary and Alternative Medicine use among Health Workers in Mid-Delta, Egypt. Majmaah Journal Health Sciences. 2013;1:2.

23. National Center for Complementary and Alternative Medicine (NCCAM). Regulation of Al-Hijamah for Practitioners and Institutions; 2015.

24. Shaheed Abd Hameed Omar. Al-Hijamah (cupping therapy): Sunnah and therapy (in Arabic). Dar Ommah for Publication, Jeddah; 2009.

25. Hany Salah Mahmoud. Scientific and practical bases of the prophetic miracle, Al-hijamah $\left(1^{\text {st }}\right.$ ed.) Dar Al Afany for Press, Cairo, Egypt. 2013;102-107.

26. Mohamed Ahmed Easa. Therapy using hijama and air cups ( $1^{\text {st }}$ ed.) Dar Al Ghadd Al-Gadid, Egypt, Almansoura. 2005;61.

27. Ilkay Zihni Chirali. Traditional Chinese medicine cupping therapy. Philadelphia: Elsevier; 2012. ISBN: 9780443102660

28. Melfy Ben Hassan. Al-Hijama (wet cupping therapy): Science and cure (in Arabic). Dar Al-mohaddeesin for publication, Cairo, Egypt. 2006;73.

29. Abo Alfidaa Mohamed Ezzat. Secrets of treatment using Al-Hijama (wet cupping therapy) and phlebotomy (in Arabic). Dar Al-fadeela for Publication, Cairo, Egypt. 2004;37.

30. Huang YL. Cupping-bloodletting therapy of Saudi Arabia and its clinical application. Zhongguo Zhen Jiu. 2008;28: 375-377.

31. Ghods R, Sayfouri N, Ayati MH. Anatomical features of the interscapular area where wet cupping therapy is done and its possible relation to acupuncture meridians. Journal Acupuncture Meridian Study. 2016;9(6):290-296.

DOI: 10.1016/j.jams.2016.06.004

32. Al-Bedah AM, Shaban $T$, Suhaibani A, Ibrahim G, Khalil M, Qureshi NA. Safety of cupping therapy in studies conducted in twenty one century: A review of literature. British Journal Medicine Medical Research. 2016;15(8):1-12.
33. Lee MS, Kim Jl, Ernst E. Is cupping an effective treatment? An overview of systematic reviews. Journal Acupuncture Meridian Study. 2011;4:1-4.

34. Cao H, Li X, Liu J. An updated review of the efficacy of cupping therapy. PLoS One. 2012;7:e31793.

35. Hssanien MM, Mansoura FS, Ahmed AF, Al-Emadi S, Hammoudeh M. Effect of cupping therapy in treating chronic headache and chronic back pain at "Al hijamah" clinic HMC. World Family Medicine Journal. 2010;8(3).

36. Khan BM, Ahmed RA, Afroz S. Partial evaluation of technique used in cupping therapy. Journal Basic Applied Sciences. 2011;1:65-68.

37. Kwon YD, Cho HJ. Systematic review of cupping including blood-letting therapy for musculoskeletal diseases in Korea. Korean Journal Oriental Physics Pathology. 2007;21:789-793.

38. Al-Bedah A, Khalil M, El-Olemy A, Elsubai I, Khalil A. Hijama (Cupping): A review of the evidence. Focus Alternative Complementary Therapy. 2011;16:12-16.

39. Liu W, Piao S, Meng X, Wei LH. Effects of cupping on blood flow under skin of back in healthy human. World Journal Acupuncture Moxibustion. 2013; 23:50-52.

40. Tagil SM, Celik HT, Ciftci S, Kazanci FH, Arslan M, Erdamar N, Kesik Y, Erdamar H, Dane S. Wet-cupping removes oxidants and decreases oxidative stress. Complementary Therapy Medicine. 2014; 22:1032-1036.

41. Zhang $L$, Tang $L T$, Tong $X L$, Jia $H$, Zhang YZ, Jiu GX. Effect of cupping therapy on local hemoglobin in human body. Zhongguo Zhen Jiu. 2001;21(10): 619-621.

42. Zeng K, Wang JJ. Clinical application and research progress of cupping therapy. Journal Acupuncture Tuina Science. 2016; 14(4):300-304.

DOI: 10.1007/s11726-016-0940-4.

43. Ibrahim Elsubai Abdullah M. N Al-Bedah, Naseem Akhtar Qureshi, Tamer Shaban Abushanab, Gazzaffi I. Ali, Ahmed Tawfik El-Olemy, Asim A.H. Khalil, Mohamed K. M. Khalil, Meshari Saleh Alqaed. The Medical perspective of cupping therapy: effects and mechanisms of action. Journal of Traditional and Complementary Medicine [Under review]. 
44. Izharul H. Encyclopedia of cupping therapy: Al-Hijama, $2^{\text {nd }}$ edition CreateSpace Independent Publishing, USA; 2015.

45. Mehta P, Dhapte V. Cupping therapy: A prudent remedy for a plethora of medical ailments. Journal Traditional Complementary Medicine. 2015;5(3):127134.

DOI:10.1016/j.jtcme.2014.11.036.PMID:26 151023

(C) 2017 El-Olemy et al.; This is an Open Access article distributed under the terms of the Creative Commons Attribution License (http://creativecommons.org/licenses/by/4.0), which permits unrestricted use, distribution, and reproduction in any medium, provided the original work is properly cited.

Peer-review history:

The peer review history for this paper can be accessed here: http://sciencedomain.org/review-history/19924 